\title{
Youtube Yinzers: Stancetaking and the performance of 'Pittsburghese' Scott F. Kiesling
}

\section{Performance, stance, class, gender}

In 1966 William Labov produced a work on the pronunciation of /r/ in New York City department stores that was, to some extent, ethnographic: Labov was a participant observer in asking for items on a particular floor of a department store, and he was familiar with the conventions necessary to find a clerk and get their attention. After a productive afternoon of finding shoes, and with the support of recordings of interviews from the Lower East Side, Labov was able to show that working-class folks tend to vocalize their $/ \mathrm{r} / \mathrm{s}$ more than middle-class folks in New York City.

One reason Labov's paper is foundational to the sociolinguistic canon is that it seems clear that Labov was able to 'control' for what was happening: Everyone he talked to was a clerk talking to a customer and was giving directions to shoes, or shirts, or some other item sold by the store. While this equivalency seems on the face of it to be an unassailable fact, the question remains whether every clerk was approaching the task in the same way: How did these clerks relate to the relatively young man in a fairly conservative but firmly middle-class suit and tie? Was he treated with the deference due to the king, as the customer should be? Or was he treated merely as some dude asking a question (perhaps a question that could have been answered by checking a 
directory)? Or, was he an incidental interaction that required little attention? Or did he ask a question the clerk was unsure of? These are all possible variations of stance that a salesclerk could take when answering such a question.

In this chapter I am going to explore the idea that local dialect is performed (in the acting sense of the word, Coupland's 2007 'high performance') when taking particular stances. I begin by asking what it means for performers to create a 'working class' identity through dialect. As Austin famously noted (although in a somewhat limited sense), language is used by people to do things. One of the main things people do with language (I argue it is the main thing) is to create relationships with other people, ideas, and things. That is, they take stances. Here I will ask what kinds of stances dialect 'high performers' take when using a particular feature of local speech to create comedy. I suggest that although the feature does not entail the expression of a single stance all the time, it tends to be used to create a stance of simultaneous opposition and alignment. The feature is the falling question intonation (FQI) on interactionally-recognizable questions, and I show that they tend to use this intonation to take an oppositional stance that is framed as 'play.' That is, in many ways there is opposition but not much investment in that alignment, so that the interaction continues in what the speakers might actually call a friendly manner.

These performances are involved in the enregisterment of 'Pittsburghese.' (Johnstone 2013). Enregisterment requires not just the typification of language, but also the typification of a fairly 
specific characterological figure, as described by Agha (2007). So stylized performances of dialect are not just context-free performances, but require the performer to inhabit a body that, along with language, takes stances. I suspect that these stances are different from those in the middle class, and possibly other places, but because of the unevenness of the data, such a claim is problematic. In general my argument will take the form that the performers are doing something at once outside the usual middle-class performed norms of video production, and at the same time are creating typical 'chracterological figures' that are recognizable to people who are from a similar place and class. In the end, the important point is that there is a describable, embodied stance associated with the characterological figure, and that these figures are generally recognizable as local (Pittsburgh), working class, and/or masculine.In Pittsburgh especially, a 'working class' stance is taken for dialect performance. I ask what it means to perform a working class identity, and show how this performance is accomplished by taking stances that focus on specific forms of negative alignment and negative assessment. These forms are emblematic not only of masculinity, but also working-class feminity, all in distinction with 'elite' forms of masculinity and femininity. This is a logical extension of the argument in Kiesling (2009), in which it is claimed that stance is the basic or primary signified upon which first-order sociolinguistic indexes of higher order (say, of identity) are created.

There is thus a significant class-gender intersectionality in the performance of dialect. Such a view is actually a more qualitative dimension of an argument made by Eckert and McConnelGinet (1999). In this argument, working class women end up being the most likely to use non middle class language, while upper working class or lower middle class women use the least 
vernacular/local sounding language.This intersectionality is important because dialect performances show both how people think of indexically linked characterological figures and reinscribe and strengthen them as these figures. In the cases I view, the videos appear on YouTube and are viewed hundreds of thousands of times.

I show how the actors in videos use a prosodic pattern typical of Pittsburgh (and some other Midland) speech — the FQI — for particular stance work. Although Fasold (1980) originally identified this intonation as marking that the speaker already knows the answer to the question, that fact is used more broadly by speakers in these videos to mock the proposition that represents the answer. This is a particular kind of stance in which the speaker asks a question that is not really question in fact, it is often absurd. But it shows the kind of oppositional stance that enregisters a particular working class 'Yinzer' persona.

To summarize, the questions are, "how does dialect get performed in terms of stance, and how is that performace related to both class and gender?” The two dimensions of identity have intersectional and interactional effect to the point that we can’t say this is a product simply of gender or class. I'll attempt this explanation, eventiually, through the ways that dialect is performed in several instances. First, I'll lay the groundwork with discussions of identity, stance, and parody. 


\section{Performed dialect}

One of the most important works on the enregisterment and performance of dialect is Johnstone's (2013) work on "Pittsburghese," the term that Pittsburghers use for the the enregistered variety of Pittsburgh speech. "Pittsbughese" appears in all types of media in Pittsburgh to the point that it is something Pittsburghers and visitors to Pittsburgh can’t avoid. Johnstone brilliantly shows not only the sociohostorical forces that produced Pittsburgh Speech, but more importantly the historical, economic, and demographic forces that led to the enregisterment of "Pittsburghese", a dialect arguably more discussed by locals than any other dialect in the US. In her book, Johnstone devotes several chapters to the performance, in various senses of the word, of Pittsburghese: She looks at public online discussions; the selling of Pittsburghese on t-shirts and talking dolls; and 'high performance” in media and in interaction. One of Johnstone's most important insights is that 'Pittsburghese' functions as an interactional resource used for different effects in these different situations (see also Johnstone and Kiesling 2008). Moreover, she shows that even for a single performance, different people may hear different identities and distinctions depending on the hearer's knowledge and experience, and only one of these interpretations relates directly to the interpretation of the speaker as a Pittsburgher with a local identity. She notes (2011:676) that “ The defining feature of linguistic performance is that it calls metacommunicative attention to itself, putting on display not only what the message means but how." This attention can then "reinforce existing form-meaning links, call existing links into question, or create new links, and which combination of these possibilities actually occurs depends on who is listening.” (2013:227) 
In other words, performances provide relexive information to hearers about how to listen to later instances of similar combinations of linguistic features. This is the insight I'd like to pursue here: that the stances taken while a particular intonational feature of Pittsburghese is performed in videos point to how to use these features in Pittsburgh speech, while at the same time reflecting the sense of how White working class Pittsburgh speakers interact. Another way to say this is that the people performing the Pittsburghese are actually enregistering characters who take habitus, which are kinds of stances. In the videos I analyze, the goal is humor, and much of this humor also relies on the fact that viewers will recognize characters they aleady know of in the videos. There is thus a dialectal relationship for these kinds of performances between "existing form-meaning links” and the creation of new links as Pittsburghers share and comment on these videos.

Coupland (2007:146-7) makes a distinction between performance in interaction and 'high performance,' as opposed to ‘mundane performance’ in everyday conversations. Coupland argues that high performance is created through seven types of communicative focusing in a speech event:

- Form-focusing: The poetic and metalinguistic functions of language [come] to the fore and considerations of 'style' in its most commonplace sense become particularly salient.

- Meaning focusing: There is an intensity, a density and a depth to utterances or actions, or at least this is assumed to be the case by audiences. 
- Situation focusing: Performers and audiences are not merely co-present but they are 'gathered', according to particular dispositional norms. People know their roles.

- Performer focusing: Performers hold a 'floor' or a 'stage', literally or at least in participants’ normative understandings of speaker rights and sequencing options.

- Relational focusing: Performances are for audiences not just to audiences. ... Although audiences are often public, performers will often have designed their performances for specific groups.

- Achievement focusing: Performances are enacted in relation to more or less specific demands. 'Stakes' (gains, losses and risks) are involved, with potential for praise or censure for good or bad performance.

- Repertoire focusing: Performers and audiences are generally sensitive to what is given and what is new in a performance. Performances may be versions of known pieces, or at least known genres. Innovative interpretation can be commended. Rehearsal is relevant.

The videos I analyze here are clearly instances of this high performance. Most relevant, style or form is central to the videos, the action is concentrated often in 2-3 minutes of video, audiences must seek and click on a play button to watch the videos, they must focus on the performers as they watch, the videos are clearly performances meant to be watched merely by way of posting on YouTube, there is a thunbs up or down button for evaluation (among other ways of evaluating), and the series creates a sense of repertoire. 
Bell and Gibson (2011:557) similarly define "staged performance” as "the overt, scheduled identification and elevation (usually literally) of one or more people to perform, typically on a stage, or in a stage-like area such as the space in front of a camera or microphone.” They also emphasize Coupland's point that "Performances tend to be for the audience, rather than simply to the audience - there is a priority to entertainand to interest, not just to communicate a message.” This aspect is important, especially in the videos I am interested in, because in this case the goal is humor. That it is successful can be seen in the comments made and displayed below the videos in YouTube. I do not analyze these comments in depth here, but it is clear from the many comments praising the humor of the videos that humor is both the expected frame and the successful one.

\section{Parody and humor}

If the goal of these videos is humor, for the most part this humor works through the recognition of particular routines and types of people in Pittsburgh who use Pittsburghese. In that sense they have the feeling of parody about the as well — a parody of the chracterological figures of 'Pittsburghese' (sometimes referred to in Pittsburgh through the label Yinzers, which derives from the use of the term yinz for second person plural pronoun). Johnstone's (2013) analysis of a 'Pittsburghese' version of the Pink Floyd song Mother deftly shows how this process can work for performance in Pittsburgh. In this radio skit, the performers intersperse the lyrics (which sound 'serious') with statements by a fictional Pittsburgh mother who uses features of 'Pittsburghese.' Crucially, Johnstone shoes that the mother is portrayed not as a soft and caring mother of the song but as a yelling, harsh, threatening mother, who can be read as working class or Pittsburgh or both. Here the inversion is the characteristic of the mother and the character of 
the enregistered White working class Pittsburgh mother, whose stances do not match up with the standard middle-class White stances of motherhood. For this to be funny, listeners need to appreciate the clash of stances in the two voices. A listener need not recognize the 'Pittsburghese mother' as working class or Pittsburgh, but if they don't then once hearing it they will be able to refer to it and its attendant stances. Those who recognize the working class and Pittsburgh identities will have another layer of humor to enjoy, and if the character is similar to a mother that they know, even another level of humor. So while parody at first temporarily inverts indexical meanings, once these inversions start to circulate, they help change indexical orders more generally. In parody, then, the indexical connection to the persona is created, changed or strengthened -- or all three at once -- highlighting a more general process.

With respect to the role of performance in circulation and enregisterment, this tells us about some of the ways that indexical connections get made. Indexicality is sometimes thought (especially in quantitative sociolinguistic work) to proceed based on frequency, but parodies show that salience or memorability of a single use is arguably at least as important. Humor is an important tool in bringing features to salience, because one way for it to be successful is when two clashing indices are brought in juxtaposition. This highlights what may have been unnoticed in a community previously. Humor also creates repeatable baptismal essentializations (Silverstein 2003), which make the circulation of the new or heightened indexical connection more likely. What is clashing in these cases is not just linguistic features (and other multimodal features such as gesture), or styles, but more centrally different kinds of stances. So at the same 
time that the parody serves to enregister the persona, it strengthens and reshapes cultural ideas of that persona.

\section{Stance}

Stance has multiple definitions in the literature (see Jaffe 2009 and Lempert 2008 for useful discussions). A classic use of the term is the epistemic stance of an utterance or speaker, which generally refers to the way a speaker knows the utterance or how certain they are about it. Another use has to do with speaker relationality or emotion, or both. Speakers can said to be 'confrontational' or 'condescending' or 'rude’ or 'angry.' In general then, stance is about a relationship of the animator (in Goffman's 1981 sense) to the propositions in their talk and their interlocutors. I define stance as the creation of relationships of speaker (animator) to some discursive figure (human or otherwise). The discursive figure is similar to Du Bois' (2007) stance object, but expands it; it can be an interlocutor, a figure represented in the discourse, the animator, ideas represented in the discourse, or other texts. This list of possible stance figures includes almost all real or imagined entities that language can represent. I will refer to it as the stance focus. I propose three simultaneous dimensions of relationship an animator creates:

- a relationship to something represented in the discourse/text,

- $\quad$ a relationship to the talk itself, and

- relationships to interlocutors.

These dimensions I refer to as affect, investment, and alignment, respectively. 
This stance triangle rests fundamentally on evaluation. In Du Bois’ terminology, two sides of the triangle are in fact the evaluation of some "stance object" by two different "subjects" (interactants, animators). The third side of the triangle is the match or mismatch between the two assessments of the first two sides. For example, in the utterance, “That's a nice watch,” that deictically picks out a copresent object as the stance object, while nice watch does the evaluative work. This utterance creates one relationship that forms one side of a stance triangle. Since the stance triangle is inherently dialogic, we need to know the next move of this statement. Let's say the compliment is accepted in a way that aligns with the compliment, something like, “Thanks, I saw it at Kaufman's and just had to have it.” In this case, the second subject evaluates the watch in a similar way as the first subject (the second sideo of the triangle), and thus aligns with that subject (the third side of the triangle).

Du Bois’ stance triangle model represented an exciting theoretical move because for once stance is grounded in specific forms and moves in discourse, and there is an algorithm for analysis. However, there are some things it misses. For one, what happens if an utterance does not involve an assessment? What is the basis for the alignment in this situation? The data I will investigate here are all about questions, and in fact the stance is being done at least ostensibly through a syntactic form that fundamentally leaves open the assertion it questions. As I will show, a simple question like “Did you get a new watch?” is arguably quite different with standard rising intonation and falling intonation I'm interested in here, in at least the sense that the latter suggests that the questioner is pretty certain that it is a new watch. Second, the stance triangle model cannot distinguish between different levels of investment (or even, arguably, epistemicity). This is because of the primacy of assessment in this model. For example, the 
utterance, “That's a nice watch" is the same as "Nice watch, dude.” At first this difference may not look like a problem, but there is a very different attempt at alignment and investment in these two utterances. In the stance triangle model, they are basically the same. This is not to say that the stance triangle model should be discarded. It contains important insights about stance and grounds the analysis of stance in a system. However, it can be expanded and built upon, perhaps even by not having a triangle at all but noticing all the different possible alignments and disalignments that speakers can make with each other in a conversation.

In order to update the model, I suggest that the thing that people are talking about or doing is the stance focus, rather than a stance object, because focus can be anything that is not even remotely object-like; the suggestion of thing-ness by 'object' is unfortunate and misleading. Let's take the example of the new watch. In the model I propose, “That's a nice watch” has a positive affect on the stance focus of the watch, which is roughly the same as the stance triangle model treats it. However, one could also say "nice watch” or "wow, that's a really swell watch you got there.” These are not equivalent on investment, even though they have the same proposition at their core, so this madel makes room for this as a separate stance dimension. Finally, in many ways “That's a nice watch" attempts to align to the addressee, in that one assumes that if someone is wearing a watch they also assessed it positively enought to purchase it and be seen wearing it. But the addressee could do work to distance themselves ("Oh, this? It’s just a twenty-dollar Timex!”) or even ignore the compliment altogether, which is probably the least aligning move one can make. Note here that we could make a distinction in alignments of the discourse management sort (in which case participating in an argument is alignment in the sense that one is cooperating to 
participate) and the propositional content sort (in which case an argument in non-aligning because there is disagreement on propositions being put forth).

In any case, what this three dimensional model of stance provides is a way to discuss the different ways stance comes into a text/conversation. I show in the analysis that these dimensions allow for a discussion of the use of the FQI in performance of Pittsburghese to enact particular figures and identities in these conversations. Of course, in humor, there is really another layer of stancetaking in that that there is an implicit stance relating to the speaker in terms of investment. That is, in humorous performance, and especially in parody, investment is inherently low because the audience is supposed to 'get' that this is not a veridical representation of real people, but exaggerations and inversions as noted in the discussion on parody. This can be taken as stipulated and not necessarily something created through the situation of high performance (although in mundane performance the signalling of performance is more important).

\section{Class}

In Labov's (1966) New York City study, class was measured through a scale of income, occupation and other factors that were correlated with linguistic variable use. As sociolinguistic work has progressed other class correlates/explanatory factors have been successfully proposed, such differences in network patterns, the linguistic marketplace, and more local categories such as "jocks" and "burnouts" in Eckert (2000; although note that she specifically shows that these categories are not exactly the same thing as other class measures, although there is some correlation with class measures). It seems, however, that class, like the term 'culture', is ever 
contested. For my purposes here, the important insight of this dispute around the theoretical object of class is that class manifests not just in consumption, practices, and beliefs, but also affects and desires. Class is thus experienced and felt, and it is something that seems to inhere deeply into bodies, and not just in the way people talk. One can see class differences in how bodies are held in conversation and even in how people walk — the hexis of class.

The idea of a hexis of class points to stances that might be relevant for the differentiation of class by stance in the United States. Hexis is borrowed from Pierre Bourdieu’s (1984) book on distinction and taste. Basically (or partially) his argument is that class distinction and taste has to do with bodily hexis, which is "a basic dimension of the sense of social orientation, is a practical way of experiencing and expressing one's own sense of social value. One’s relationship to the social world and to one's proper place in it is never more clearly expressed than in the space and time one feels entitled to take from others; more precisely, in the space one claims with one's body in physical space, through a bearing and gestures that are self-assured or reserved, expansive or constricted ... and with one's speech in time, through the interaction time one appropriates and the self-assured or aggressive, careless or unconscious way one appropriates it.” Bourdieu (1984:474)

I suggest that this “practical way of experiencing one’s own sense of social value” encompasses the habitual stances that people take to one another, to strangers, friends, loved ones, colleagues, co-workers and even department store customers. Indeed, the habitus that is Bourdieu's hallmark 
could be understood as habitual stancetaking. My argument is then that if class (or distinction, or taste) is hexis-based, and stance is not a deliberative activity but habitual and included in hexis, then stance is also implicated in class. Furthermore, if stance is largely, but not completely, achieved through talk, then it stands to reason that stance is fixed at the center of the process of the social stratification of linguistic variation. Finally, we should be able to see this bodily hexis created in performances of (working class) dialect because these performances are not parodies of speech only, but of the characterological figures that encompass all aspects of identity that includes comportment — bodily hexis.

So what characterizes the interactional, affective and hexis-based distinction between working class and middle class among Whites ${ }^{1}$ in the US? How is “working-class White” enregistered in Pittsburgh in ways beyond Pittsburghese? Johnstone (2013:192-194) provides an excellent extended discussion of the the interactional and affective dispositions that could characterize class. Her most important insight is the role of opposition in working class affect. For example, in his ethnography of working class culture in Thunder Bay, Ontario, Dunk (1991) shows how opposition saturates the interactions he discusses. This opposition takes many forms, but is true both with friends and with those they don't like. At work, 'the boys' see themselves as opposed to management who are there simply to exploit them. On the other hand, opposition is also a factor in the kinds of stances they take while hanging out with friends, although in this context it is interpreted as alignment (see also Schiffrin’s 1984 analysis of Jewish argument as sociability for a more linguistic example of how disalignment can have the effect of alignment). This 'banter' can also be often found in 'masculine' interactions in the US (see Kiesling 2005). 
Oppositional stances here can refer to things like insults, making fun of someone, telling someone they are doing something wrong, disapproval, and simply disagreeing with assertions. In other words, ways in which there is some sort of propositional content or speech act disalignment. In general then, this stancetaking will show up in the alignment dimension in the stance model discussed above; however, in the sense that negative evaluations are also oppositional, it also manifests itself in affect. In terms of investment, I suggest that disalignment is achieved with higher investment (i.e., more 'direct') for the same evaluation, although there is less investment in situations that are not inherently non-aligning.

Of course, no person has one identity, and this is true of performers as well. People come as bundles of possible identity categories and live lives based on all of them simulataneously, or in intersection (Crenshaw 1991). I am putting aside for the most part a discussion of intersection with race because in the context I'm analyzing, everyone is assumed to be White. This observation of course has implications for an analysis of race, class and language, but there's no space here to explore this dimension further. I will simply note that the invisibility of Blacks in the videos and in many discussions of class would be the place the start with a race-class analysis in this context.

Class and gender are the complicated intersection I wish to interrogate here. Gender traditionally (and still, for many people) has only two categories. Sometimes these categories are felt as poles on a continuum, bsut more recently this binary view has been challenged. There is no space here for an extended discussion of the definition of gender (it changes based on the order of analysis, among other things). However, it is clear that gender and class are not (easily) separable, certainly not in the enregistered identities discussed here. Eckert and McConnell-Ginet (1999) 
suggests that working-class femininity differs from middle-class femininity in ways that the comparable masculine categories do not. She provides data that show this interaction for sociolinguistc variation. One reason this analysis manifests is the clash between ideal femininity and working class stances, whereas for masculinty there is no such clash. That is, roughly speaking, ideologies — and language behavior — about femininity suggest stances of accommodation and politeness (see Lakoff 1975 and Holmes 1995), while more oppositional and dominating stances are shown for masculinity (see Kiesling 1997, 1998). The stances encoded through working class speech for women are often seen as emblematic of violating norms of sexual purity through a metaphor of linguistic contamination. In the videos I analyze, gender is in many ways both heightened and erased, especially in the use of FQI.

\section{Falling Question Intonation $\left(L^{*}+H L \%\right)$}

The feature I'm exploring in these videos is one that is shared throughout the eastern Midland dialect area of the US. Fasold (1980) is one of the first to describe this intonation, which exhibits a low to quickly rising tone on the phrase accent similar to 'canonical' questions, but instead of a final rise shows a precipitous fall. I refer to this contour as “Falling Question Intonation” or FQI. The contour is represented in the ToBI notational system (Beckman, Hirschberg, ShattuckHufnagel 2006) as $\mathrm{L}^{*+\mathrm{H}} \mathrm{L} \%$. In this notation, “ $\mathrm{L}^{*}+\mathrm{H}$ ” represents the low rising tone, while " $\mathrm{L}$ \%” represents the falling tone at the end (which would be $\mathrm{H} \%$ in a canonical American English question). ${ }^{2}$ To a native speaker of (non-Pennsylvanian) American English, this intonation is quite noticable and salient. Fasold suggested in his description, based on its use in the English spoken by the Amish of central Pennsylvania, that this intonation tended to be used when the answer was 
already generally known by the questioner. For example, if Sophie is eating ice cream voraciously and not really taking note of anything going on around her, Bob might ask

"You like that ice cream Sophie?"

$\mathrm{L}^{*}+\mathrm{H} \quad \mathrm{L} \%$

Based on the evidence of how she is eating the ice cream, Bob already knows she likes the ice cream (and ice cream is usualy something people like anyway), but he is asking the question nevertheless. This allows speakers to ask more obvious questions that provide an opportunity to continue the interaction.

Figure 1 provides an example from the data labeled using the ToBI conventions on a waveform. (The word here is indeed hangry and not hungry. The speaker (Donny) is asking the addressee (Greg) is he is in a bad mood because he is hungry; hangry is a relatively new American English term that blends hungry and angry.) This figure provides a clear picture of the fall-rise-fall pattern that typifies this contour. In this example, it begins at the word hangry. 


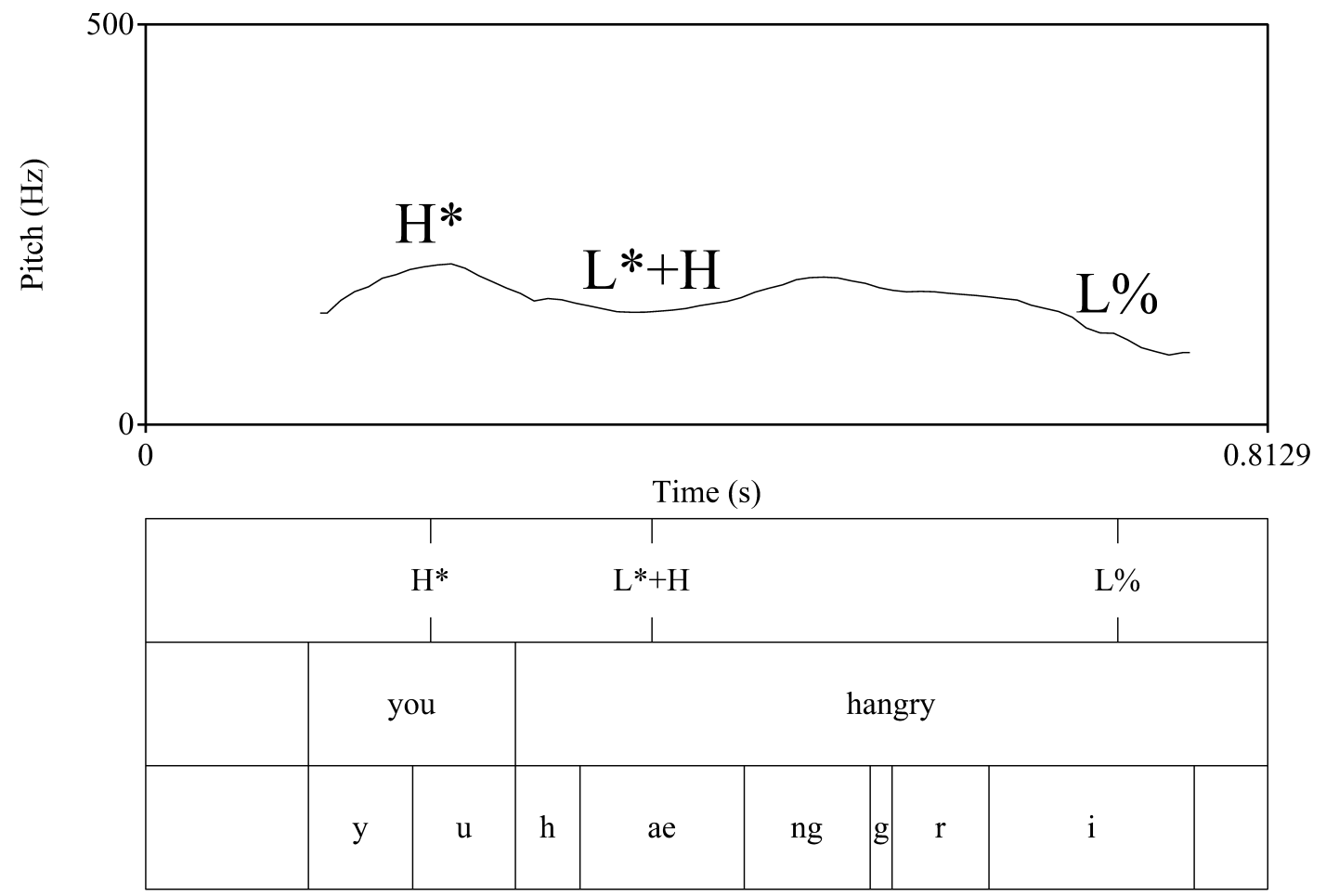

Figure 1: Pitch track of an example of the $\mathrm{L}^{*+\mathrm{H}} \mathrm{L} \%$ falling question intonation.

Hedberg et al (2014) provide support more generally for the potential meanings of FQI. They present a corpus-based study of the meaning of different intonation contours of American English questions. They argue that the falling questions in their corpus are all in some way 'nongenuine,' or more precisely one or more of the felicity conditions for the question is violated. Certainly knowing the answer to a question is a violation of a normal requirement for questions that the questioner not know the answer, as is the mocking stance that I find on some of these 
questions. There may be other stance indexicalities such as condescension which hold; this possibility is explored further in the analysis in the next section.

\section{Greg and Donny}

The videos that I analyze are part of a YouTube series called Greg and Donny (REF), most of which are under 5 minutes. The videos present conversations among 2-5 friends who live in Johnstown, Pennsylvania, an industrial town about 100 km from Pittsburgh (this distance counts as close in the United States). The opening conceit of the videos (first posted in April 2009: Greg \& Donny Discover Video Chat) is that the friends (and neighbors) Greg and Donny have just discovered video chat. Each video is usually two to four minutes long, although they range from one minute to over seven. The topics are usually mundane or are about Pittsburgh cultural traditions, or holidays (especially Halloween and Christmas/New Year's Eve). The characters expanded to Greg’s wife, Gina, and Greg and Donny’s friend, Missy Kreutzer (usually only referred to by her last name, the spelling of which is not given and is an educated guess). The episodes are thus composed of conversations among the friends, usually from two vantage points (computers) but sometimes from three, as in the video analyzed below. If there are more than two people in the episode then there will be more than one person visible on each computer. The focus of the interactions is not explicitly on the way people talk, with the exception of one brilliant episode in which Greg travels to Philadelphia and reports back that people are mocking his accent. However, the episodes are written to be dense with recognizable features of “Pittsburghese” or 'phono-opportunities' as Coupland (1985) calls them. For example, the episode excerpted below (Idlewild) in which Kreutzer reports on her visit to the Idlewild amusement park, provides multiple opportunities not only to reference the cultural proactice of 
visiting this park, but the vocalization of /l/, since /l/ appears twice in the name of the park, both times in coda position where it is likely to be vocalized (it's interesting as well that the Kennywood amusement park is usually taken to be stereotypically Pittsburgh). In short, the videos are comedy skits about working class people in southwestern Pennsylvania, and language is for the most part performed without metapragmatic comment. The comments sections, however, show many comments that focus both on the use of perceived "Pittsburghese" and the interactional patterns the characters use.

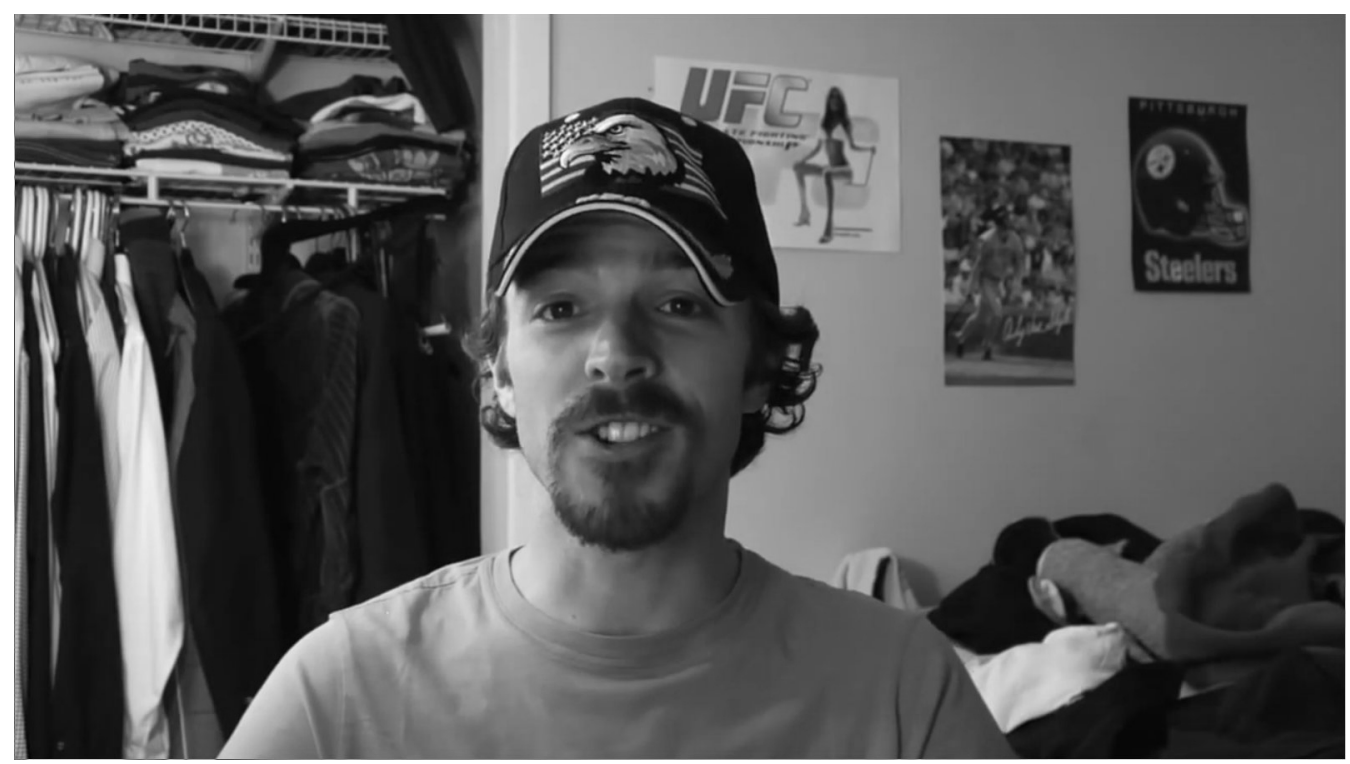

Figure 2: Frame of Donny from the "Idlewild" episode. Approximately line 51 in the transcript. 


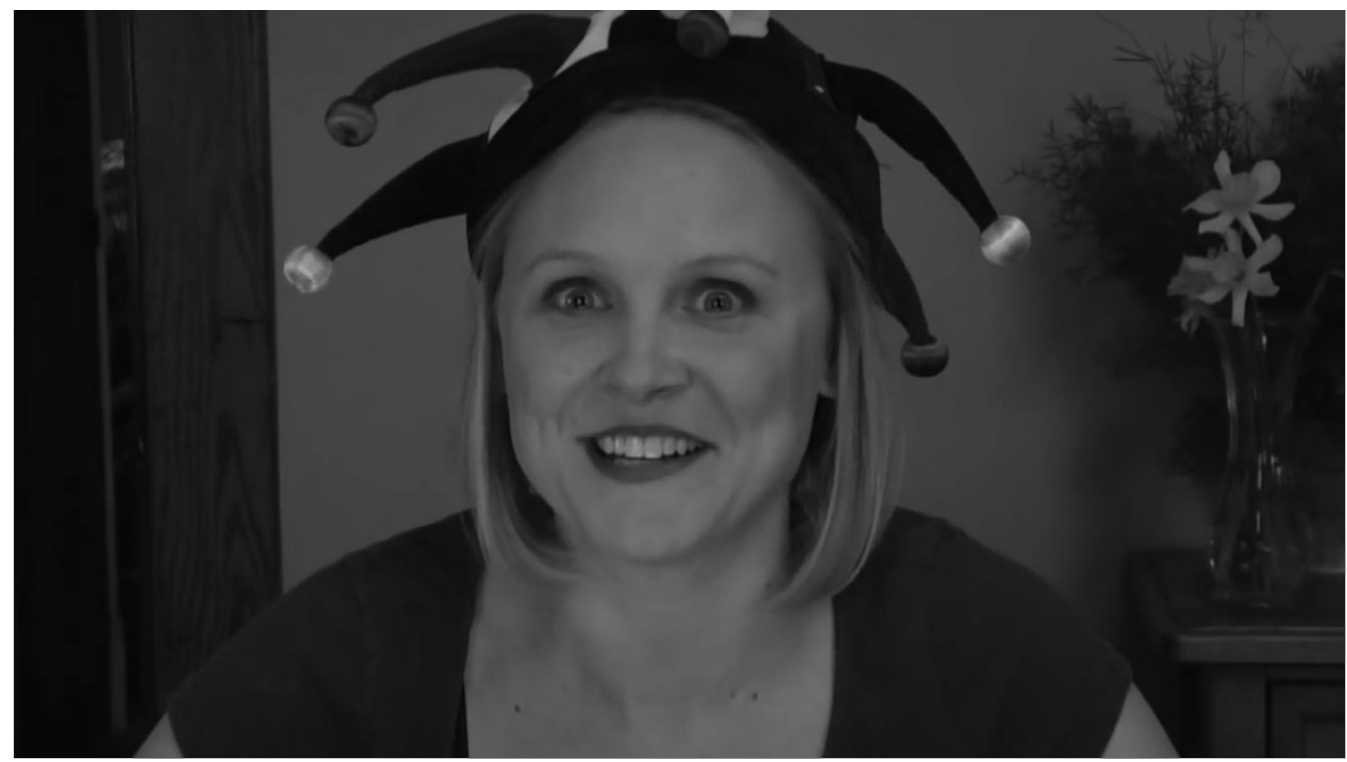

Figure 3: Frame grab of Kreutzer from the "Idlewild" episode. Approximately line 50 in the transcript.

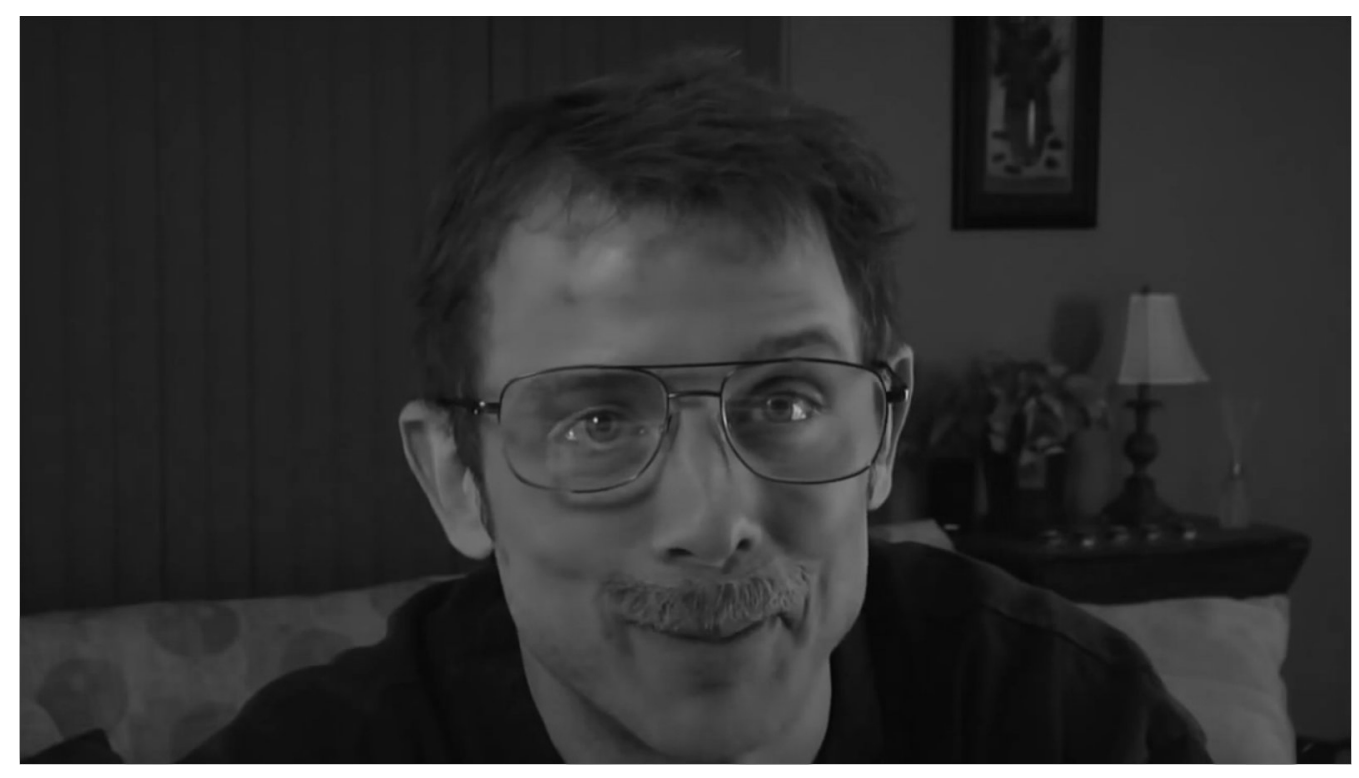

Figure 4: Frame grab of Greg from the "Idlewild" episode. Approximately line 50 in the transcript. 
As representations of working class culture in Southwestern Pennsylvania, the kinds of interaction presented in the videos is meant to represent and parody the typical people who live there, and their characteristic interaction. In terns of stance, disalignment is the norm, even as the 'banter' creates solidarity. LQI is a resource that some characters, especially Donny, use to help with this playful opposition. As an example, I examine some talk from the Idlewild episode. I've provided three frame captures of the three characters for this video in figures two through four. The except begins after a short section in which Donny and Kreutzer criticize Greg for not going to Idlewild the previous summer, and he defends himself. Donny then shifts back to Kreutzer's recent visit to the theme park, asking whether she rode a particular ride.

\section{Excerpt}

30 Donny: Yinz ride the Spider Kreutzer?. ((LQI))

31 Kreutzer: I don't like that ride

32 Donny: Ah that's the best ride

33 Kreutzer: Spiders are creepy

34 Greg: I like the coaster. Always been a coaster man

35 Donny: What'd you ride Kreutzer, the uh, choo-choo in Storybook Forest?

36 Kreutzer: Nice try Smozik

37 Storybook Forest don't got a choo-choo

38 Greg: Don't go knockin' Storybook Forest

39 You know I had a crush on that Goldilocks

40 PAUSE

41

Gina don't like me bringin' that up

42 Gina: ((off camera)) Quit talkin about that Goldilocks or I'm gonna come in there and pop you one Greg 
43 Kreutzer: You wanna see what I won?

44 Greg: [Alright

45 Donny: [Alright

46 Kreutzer: Well do you or don't you?

47 Greg: A[lright

48 Donny: [Alright

49 Kreutzer: ((goes off camera to put on a jester hat))

Ta Da: ((reveal singsong intonation))

$50 \quad$ Isn't it cool?

51 Donny: Yinz gonna wear that out Kreutzer?. ((LQI))

52 Greg: That'd be a sight to see

53 Kreutzer: No I'm not gonna wear it out

54 Donny: Haha 'cause I'd tell you to take a picture of yourself if you did cause uh:

55 I'd like to see a picture of that

56 Greg: You could send that in to Jay Leno ((host of The Tonight Show at the time))

57 Kreutzer: Oh now it's Laurel and Hardy over there is it?

$58 \quad$ You're a real couple of Abbott and Costellos

59 Greg: Hey Donny who's on first?

60 Kreutzer: [What?

61 Donny: [ Huh?

62 Greg: I was just asking Donny who's on first

63 Kreutzer: How's come?

64 Donny: What the hell you talkin' 'bout Greg?

65 PAUSE

66 Greg: Ah never mind I ain't explainin' it 
67 Kreutzer: Anyhow

68

69

I ain't wearin' the hat

I'm just gonna keep it on the shelf for the memory

((the video continues))

Donny (who uses LQI the most of all characters) uses LQI on his question in line 30, including using a Pittsburghese feature (yinz), although he uses it to address only Kreutzer (yinz is usually a plural address form; nevertheless one could imagine he is also referring to the people Kreutzer presumably went to the park with). In any case Donny asks this question with a devilish smile (in Figure 2 he is in the midst of this utterance), perhaps because he knows it is a stomach-churning ride, according to the park website, "riders hold on tightly as they are tossed, dipped, and spun in every direction”; “Adventures, Rides, and Shows at Idlewild”, 2016). When Kreutzer says she didn’t ride the Spider, Donny disaligns with her by implicitly criticizing her choice (line $32 \mathrm{Ah}$ that's the best ride), and Greg goes on on in line 34 to simply say what he likes (I like the coaster. Always been a coaster man). None of these moves is particularly aligning except to be on the topic of rides at Idlewild.

Donny asks Kreutzer in a mocking tone in line 35 whether she rode a 'choo-choo’ in the Storybook Forest, which is, according to the description from the park (“Adventures, Rides, and Shows at Idlewild”, 2016) “a very special place where little ones can meet their favorite characters from nursery rhymes and children's tales and where parents and grandparents can revisit their youth and reminisce about simpler times.” In other words, it’s a section of the park for little kids, so he’s making fun of her by saying she stayed in the ‘kiddy’ part of the park. Note that Kreutzer's response to this is to call Donny out on his knowledge of the park. 
When Kreutzer shows her hat and asks if it's cool in line 50, rather than agreeing that it's cool, Donny mocks her with the question he asks about wearing the hat out in line 51 . Kreutzer defends herself from the mocking by suggesting it's not funny by ironically calling the two men Laurel and Hardy and Abbott and Costello. The next section is tangential, in which Greg tries to reference the classic Abbott and Costello routine Who's on First? but the other two are apparently unfamiliar with it.

After this excerpt, the three go on to argue about what kind of memory is worthy of "keeping on a shelf." Nevertheless, this short section displays the kind of oppositional banter that is typical of the series. The women display some traits ideologically associated with masculinity, including the opposition of Kreutzer and Gina’s threat to hit Greg (line 42, Quit talkin about that Goldilocks or I'm gonna come in there and pop you one Greg). The fact that Kreutzer is referred to by her last name and not Missy, her first name, is also a way of making her more 'one of the boys,' as last name only address is common among American men and less common for women.

The two uses of LQI by Donny are characteristic of how he uses them throughout the series. The mocking in these uses is not complete and is anticipatory, and sometimes doesn't work out because he might have guessed the answer to the question wrong. In the case of the question about riding the Spider in line 30, it's possible to hear that he wanted to make fun of Kreutzer because of her reaction to riding a ride that spins the riders so much. The question about wearing the hat out in line 51 suggests that he does not think it is cool (which is what Kreutzer asks in the turn before), but rather evaluates it as something one might not want to be seen in public wearing. So both of these uses of LQI evince a mocking tone which disaligns through a negative 
affect in the sense of belittling what she is doing or has done. However, it does so in a way that shows lower investment in the criticism, in the sense that Donny can claim he is 'only joking.'

Gina is the other characer who uses LQI regularly in the series. She tends to use the contour to express effrontery or outrage. In one episode (Greg has an accent) she aligns with Greg against people who find his accent funny by asking “Are they makin’ fun of you?” with the LQI contour. And in another she sees Greg folding her ‘snuggie’ as if to put it away, and says, enraged, “Is he foldin’ that snuggy?” with LQI. So in a different way that fits her character, Gina uses LQI in opposition as well. Although LQI is not the only contour to be used oppositionally, it tends to be

used that way more than other question intonations. Note that Donny asks about the "choo-choo in storybook forest” with a rising intonation. The difference is that in this question the mocking is in the diminutive, childish form of "choo-choo" and would be hard to imagine if Kreutzer's response is correct.

LQI in this video thus helps to signal that the lower investment of the negative alignmentFigure 4: Frame grab of Greg from the "Idlewild" episode. Approximately line 50 in the transcript. is detected; that is, it signals that the frame is one of banter with the goal of furthering social interaction and friendship even as there is apparent conflict.

\section{Stance, class, and enregisterment}

One of the most common markers or responses in these videos is “Aw Jeez," an expletive of exasperation derived from the blasphenous “Ah Jesus.” This response is usually a marker of disapproval and at the same time sympathy for the addressee. Throughout these videos, we see disalignment and even confrontation, apparent glee in another tribulations, but in the end a kind 
of camaraderie emerges. This stance of simultaneous local disalignment but overall interactional alignment — they are talking to each other after all — is represented as typical working class “Yinzer” interaction. Viewers in the comments find it to be fairly authentic. In general, only those who mistake the accent (for example, thinking it is supposed to be "southern") criticize the authenticity, and many comment on the authenticity not just of the dialect performances but of the overall interaction as well. LQI is one device to support this authenticity and this stancetaking.

So these videos both serve to enregister these personae and to re-enregister them, and help them circulate. They are typified by an oppositional stance within rather everyday banter that appears 'natural' to viewers familiar with this culture, and rather than responding with outrage, generally comment with recognition and even at times nostalgia. The performed dialect this re-enregisters not only the way of speaking, but the way of being in speaking Pittsburghese.

\section{Appendix: Transcription conventions}

The transcript is produced in the simplest manner possible, with very little in the way of detail remarks, for legibility. The details that matter for the conversation, such as where LQI is located, are noted. Most of the talk is in "Pittsburghese” pronunciation, and no attempt is made to specifically transcribe that since it is understood and would be distracting to read. Each speaker is generally shown when they speak, with the head shot frame shown in the figures.

Pauses longer than one second are transcribed on their own line with 'PAUSE'.

LQI and transcriber comments about the transcript are in ((double parentheses)). 
Overlaps are marked with square brackets at the point of overlap.

\title{
Appendix: Full transcript of video Idlewild
}

\author{
01 Kreutzer: ((eating cotton candy)) Did I do it right? \\ 02 Guys \\ 03 Donny: Kreutzer \\ 04 Greg: How many people are seein' me? \\ 05 Kreutzer: Huh? \\ 06 Greg: How many people are on this? \\ 07 Donny: Just us Greg \\ 08 Greg: You can talk to one than more person on this? \\ 09 Donny: Yes, Greg \\ 10 Greg: Can you talk to a hundred? \\ 11 Donny: No Greg three \\ 12 Greg: Didn't know you could talk to more than one person on this. \\ 13 Greg: [whisper] \\ 13 Greg: Where'd you get that cotton candy Kreutzer? \\ 14 Kreutzer: Just got back from Idelwild \\ 15 Donny: That's open al ready? \\ 16 Kreutzer: Where you been Smozik? ((Donny's last name)) \\ 17 Greg: Gina and me will have to make time to go this year \\ 18 Donny: You didn't go to Idlewild last year? \\ 19 Kreutzer That ought to be illegal \\ 20 Donny: C'mon Greg that's a tradition \\ 22 Greg: I just got too much going on. \\ 23 Kreutzer: Oh that's right Donny, we forgot, teachers are real busy over \\ Donny: Eatin' bon bons \\ Greg: Alright last summer we built them deck chairs, stripped down \\ the fireplace, cut down them shrubs, Gina got book club, \\ babysittin' Bob Nooner's cat, weekends we go down Periwinkle \\ Village in Ligonier go shoppin' for Santas \\ Kreutzer: God, stop talkin' al ready \\ 29 Greg: ( (sigh)) \\ 30 Donny: Yinz ride the Spider Kreutzer ((LQI)) \\ 31 Kreutzer: I don't like that ride \\ 32 Donny: Ah that's the best ride \\ 33 Kreutzer: Spiders are creepy \\ 34 Greg: I like the coaster. Always been a coaster man \\ 35 Donny: What'd you ride Kreutzer, the uh, choo-choo in Storybook

\section{Forest?} \\ 36 Kreutzer: Nice try Smozik \\ 37 \\ 38 \\ 39 \\ 40 \\ 41 \\ Greg: \\ Storybook Forest don't got a choo-choo \\ You know I had a crush on that Goldilocks \\ PAUSE \\ Gina don't like me bringin' that up
}


42 Gina: Quit talkin about that Goldilocks or I'm gonna come in there and pop you one Greg

43 Kreutzer: You wanna see what I won?

44 Greg: [Alright

45 Donny: [Alright

46 Kreutzer: Wel do you or don't you?

47 Greg: A[lright

48 Donny: [Alright

49 Kreutzer: Ta Da: ((reveal singsong intonation))

$50 \quad$ Isn't it cool?

51 Donny: Yinz gonna wear that out Kreutzer? ((LQI))

52 Greg: That'd be a sight to see

53 Kreutzer: No I'm not gonna wear it out

54 Donny: Haha 'Cause I'd tell you to take a picture of yourself if you did cause uh

$55 \quad$ I'd like to see a picture of that

56 Greg: You could send that in to Jay Leno ((host of The Tonight Show at the time))

57 Kreutzer: Oh now it's Laurel and Hardy over there is it?

58 You're a real couple of Abbott and Costellos

59 Greg: Hey Donny who's on first?

60 Kreutzer: [What?

61 Donny: [ Huh?

62 Greg: I was just asking Donny

63 Kreutzer: How's come?

64 Donny: What the hell you talkin' 'bout Greg?

65 PAUSE

66

67

68

69

Greg: $\quad$ Ah never mind I ain't explainin' it

Kreutzer: Anyhow

I ain't wearin' the hat I'm just gonna keep it on the shelf for the memory

Donny: What kind of memory is that?

Kreutzer: Any kind of memory I say it is Donny

Greg: Memories are important Donny

Kreutzer: Yeah Donny

Butt out

Greg: Like when I was goin' with Goldilocks ((said quietly))

Gina: Dammit Greg

Donny: Stuff you put on the shelf's gotta be a real memory, like a baseball autgraphed by Reggie Jackson

Kreutzer: That ain't a memory Donny

You won it at flippin' cards

Donny: Well yeah it's the most I every won at flippin'

Kreutzer: Well this the most I ever won at knockin' over milk jugs

Donny: Yinz get all three?

Kreutzer: On the floor

Greg: Ahhh them games are rigged

They rig them so you can't win

Kreutzer: [I did win

Donny: [ She did win

88 Greg: Yeah they do them to all them games make them seem real simple 


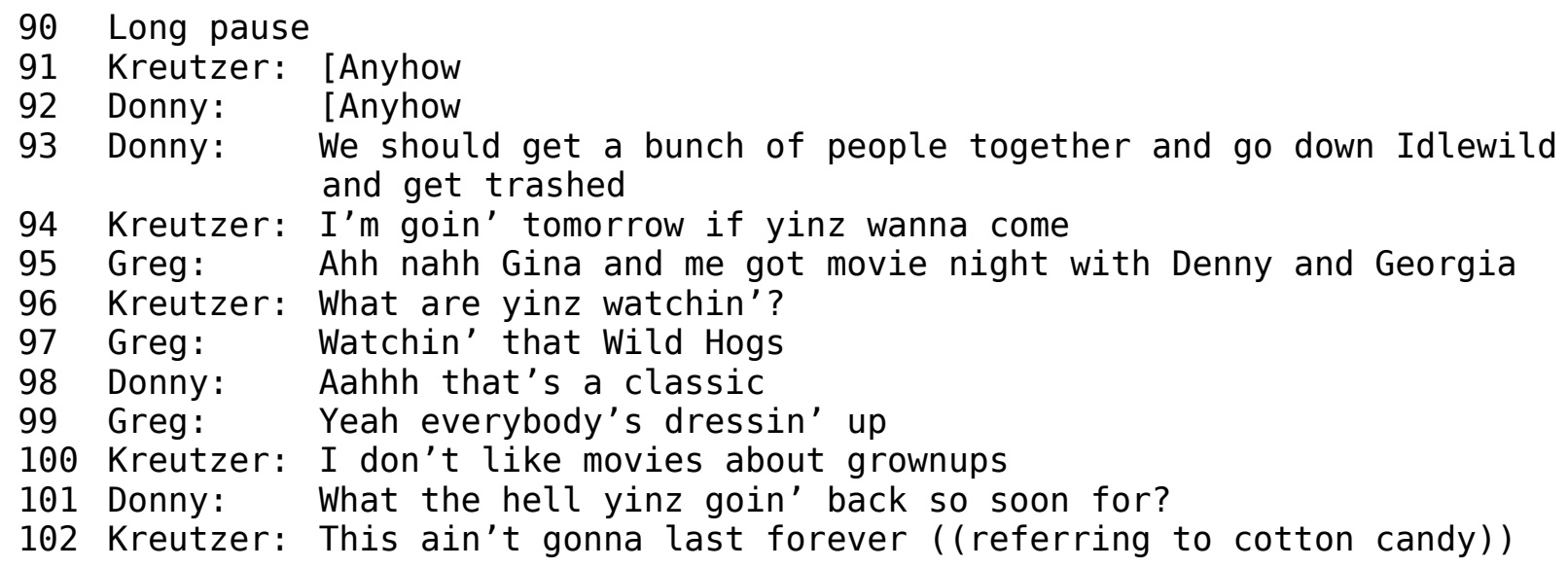

\section{References}

Adventures, Rides, and Shows at Idlewild. (2016, December 10). Retrieved from https://www.idlewild.com/things-to-do/attractions

Agha, A. (2007). Language and Social Relations. Cambridge: Cambridge University Press.

Beckman, M. E., Hirschberg, J., \& Shattuck-Hufnagel, S. (2006). The Original ToBI System and the Evolution of the ToBI Framework. In Sun-Ah Jun (ed.), Prosodic typology: The phonology of intonation and phrasing (pp. 9-54). Oxford and New York: Oxford University Press.

Bell, A., \& Gibson, A. (2011). Staging language: An introduction to the sociolinguistics of performance. Journal of Sociolinguistics, 15(5), 555-572. https://doi.org/10.1111/j.14679841.2011.00517.x

Bourdieu, P. (1984). Distinction : A Social Critique of the Judgement of Taste. Harvard University Press.

Coupland, N. (1985). “Hark, hark, the lark”: Social motivations for phonological style-shifting. Language and Communication, 5(3), 153-171. https://doi.org/10.1016/02715309(85)90007-2 
Coupland, N. (2007). Style : Language Variation and Identity. Cambridge, UK; New York: Cambridge University Press.

Crenshaw, K. (1991). Mapping the margins: Intersectionality, identity politics, and violence against women of color. Stanford Law Review, 43(6), 1241-1299. https://doi.org/10.2307/1229039

Du Bois, J. W. (2007). The Stance triangle. In R. Englebretson (Ed.), Stancetaking in Discourse (pp. 139-182). Philadelphia: John Benjamins Publishing Company.

Du Bois, J. W., \& Kärkkäinen, E. (2012). Taking a stance on emotion: Affect, sequence, and intersubjectivity in dialogic interaction. Text and Talk, 32(4), 433-451. https://doi.org/10.1515/text-2012-0021

Dunk, T. (1991). It's a Working Man's Town: Male Working-class Culture. Montreal: McGillQueen's University Press.

Eberhardt, M. (2008). The Low-back merger in the Steel City: African American English. American Speech, 83(3), 284-311.

Eberhardt, M. (2012). Enregisterment of Pittsburghese and the local African American community. Language \& Communication, 32(4), 358-371. https://doi.org/10.1016/j.langcom.2012.08.002

Eckert, P. (2000). Linguistic Variation as Social Practice. Malden, Mass.: Blackwell Publishers.

Eckert, P., \& McConnell-Ginet, S. (1999). New generalizations and explanations in language and gender research. Language in Society, 28, 185-201.

Fasold, R. W. (1980). The conversational function of Pennsylvania Dutch question intonation. New Ways of Analyzing Variation Conference. Washington, DC. 
Goffman, E. (1981). Footing. In Forms of Talk. Philadelphia: University of Pennsylvania Press. Hedberg, N., Sosa, J. \& Görgülü, E. (2014). The meaning of intonation in yes-no questions in American English: A corpus study. Corpus Linguistics and Linguistic Theory. Retrieved from doi:10.1515/cllt-2014-0020

Holmes, J. (1995). Women, Men and Politeness. London: Longman.

Jaffe, A. M. (2009). Introduction: The Sociolinguistics of Stance. In Stance: Sociolinguistic Perspectives, A. Jaffe (ed.), pp. (3-28). Oxford; New York: Oxford University Press.

Johnstone, B. (2011). Dialect enregisterment in performance. Journal of Sociolinguistics, 15(5), 657-679.

Johnstone, B. (2013). Speaking Pittsburghese : The story of a dialect. New York ; Oxford: Oxford University Press.

Johnstone, B., \& Kiesling, S. F. (2008). Indexicality and experience : Exploring the meanings of /aw/-monophthongization in Pittsburgh. Journal of Sociolinguistics, 12(1), 5-33. https://doi.org/10.1111/j.1467-9841.2008.00351.x

Kiesling, S. F. (1997). Power and the language ofmMen. In S. Johnson \& U. Meinhof (Eds.), Language and Masculinity (pp. 65-85). Malden, MA; Oxford: Wiley-Blackwell.

Kiesling, S. F. (1998). Men’s identities and sociolinguistic variation: The case of fraternity men. Journal of Sociolinguistics, 2(1), 69-99. https://doi.org/10.1111/1467-9481.00031

Kiesling, S. F. (2005). Homosocial desire in men’s talk: Balancing and re-creating cultural discourses of masculinity. Language in Society, 34(05), 695-726. https://doi.org/10.1017/S0047404505050268

Kiesling, S. F. (2009). Style as stance: Stance as the explanation for patterns of sociolinguistic 
variation. In A. Jaffe (Ed.), Stance: Sociolinguistic Perspectives (pp. 171-194). New York: Oxford University Press.

Labov, W. (1966). The Social Stratification of English in New York City. Washington: Center for Applied Linguistics.

Lakoff, R. T. (1975). Language and Woman's Place. New York: Harper \& Row.

Lempert, M. (2008). The poetics of stance: Text-metricality, epistemicity, interaction. Language in Society, 37(04), 569-592. https://doi.org/10.1017/S0047404508080779

Schiffrin, D. (1984). Jewish argument as sociability. Language in Society, 13(03), 311-335. https://doi.org/10.1017/S0047404500010526

Silverstein, M. (2003). Indexical order and the dialectics of sociolinguistic life. Language \& Communication, 23(3-4), 193-229. https://doi.org/10.1016/S0271-5309(03)00013-2

\section{Notes}

1 It is important to keep in mind that the discussion of Pittsburghese also encodes race, mainly by enregistering Pittsburghese as a White variety. See Eberhardt $(2008,2012)$ for a discussion of race and language from the Black standpoint. I use the terms White and Black because I believe the euphemisitic distinctions attempt to scientize and erase the cultural significance of the categories, and make race less oppositional than it is.

2 Many thanks to Shelome Gooden for help with the ToBI notation of this pitch contour. 